\title{
Cavitating Fuel Flows in Hypocycloid Pump from the Perspective of Applying the Effect of Gas Desorption from The Solution with Nucleation of Gas Bubbles
}

\author{
Wojciech Karpiuk ${ }^{1}$
}

1 Faculty of Transport Engineering, Poznan University of Technology, ul. Piotrowo 3, 61-138 Poznan, Poland e-mail: wojciech.karpiuk@put.poznan.pl

\begin{abstract}
This article focuses on the cavitation mechanism from the perspective of utilizing the effect of gas desorption from the solution with nucleation of gas bubbles. This effect is an innovative approach to improving the operating parameters, including emissions parameters, in the compression-ignition engines. The article presents the concept of applying this process in practice and draws attention to the problems associated with its practical implementation. With regard to this issue, an original pump design with a hypocycloid power transmission, enabling application of the desorption effect, was presented. The second part of the article focuses on evaluating the possibility of cavitation occurring in the pump. This task was realized by simulating the cavitating flows in the pump's return valve - the site at the greatest risk of formation of the first nuclei of this unfavorable phenomenon.
\end{abstract}

Keywords: cavitation, hypocycloid pump, injection systems, compression ignition engine, gas desorption, CFD

\section{INTRODUCTION}

Undoubtedly, one of the most serious problems of the modern compression-ignition engines is the excessive emission of harmful substances in the exhaust gases. The measures intended to reduce the negative impact of machines of this type on the environment are determined by increasingly stringent emissions standards. This problem is being solved in multiple aspects - from the application of aftertreatment $[23,5$, $6]$ systems or alternative fuels $[12,3]$, through optimization of the combustion process, to significant modifications of the current designs [ 28 , $19,2]$, or even replacement of the classical combustion engines with the electric engines. These are just some of the methods being applied - the fact is that the efficacy of individual methods varies. Various types of comparisons between the conventional and electric engines also differ - this is shown by the ambiguous results of studies $[4,20]$. The goal of this introduction is not to conduct such a comparison, which would require an in-depth and multi-criteria analysis. Nevertheless, total emissions (particularly of harmful $\mathrm{CO}_{2}$ ) must be accounted for, from extraction, through use, to disposal, particularly in the case of the electric engines. This is because the extraction and processing of lithium, cobalt and manganese, i.e. the elements used to manufacture batteries, contributes substantially to the total greenhouse gas emissions. Combined with the fact that the cars with electric engines are used in the countries where the coal-fired power plants are operating and the still arising process of recycling spent batteries, the report [4] shows that the vehicles with electric engines may emit $11 \%$ to $28 \%$ more $\mathrm{CO}_{2}$ compared to the combustion engines.

Considering this brief presentation of the current state of affairs and the fact that the infrastructure for servicing electric vehicles is still in its infancy, it can be stated that the combustion engines will remain the primary drive for passenger vehicles for a long time. Therefore, the measures intended to improve the emission 
parameters of the combustion engines should be continued. Optimization of the injection process, which in turn, is associated with the combustion process, presents large capabilities in this scope - particularly in the compression-ignition engines equipped with common rail (CR) systems. A trend that has been observed in the injection systems for many years is the continuous increase of the injection pressure [22, 14, 13, 27]. This is linked to the capability of reducing the mean diameters of fuel droplets, which fosters mixing with air. Only at very high pressures, above $180 \mathrm{MPa}$, can noticeable improvement of emissions parameters and improvement of fuel consumption be observed. However, constantly raising the injection pressure does not solve the problem at hand. Studies [8] showed that increasing the injection pressure above $200 \mathrm{MPa}$ does not bring clear benefits with regard to the emissions of pollutants. Other problems concerning the manufacturing and use of injection systems placed under such high stress must also be kept in mind. These issues are associated with, among other things, leaktightness, dimensional stability, and above all, the durability of high-pressure systems (injection pumps, injectors).

Hence the question: must the development of injection systems, which determine emissions of harmful substances to a large extent, be associated with an increasing injection pressure? Is that the only way forward? This article discusses an alternative approach to the issue.

\section{Application of desorption effect in hypocycloid pump and cavitation}

As the results of studies [16, $18,17,15]$ show, there is another solution to the problem presented in the introduction - in his works, Kozak proposed an innovative concept of improving the spraying mechanism, based on the introduction of gas into Diesel, which may be exhaust gases $\left(\mathrm{CO}_{2}\right)$, air or CNG. The gas that is introduced must be compressed in the highpressure pump so that it is dissolved in the fuel. At that point, the idea assumes the obtainment of an equilibrium solution, which is transported via high-pressure lines to the standard fuel rail of the CR system, after which it goes to fuel injectors. At the time of injection, a thermodynamic stimulus, in the form of a negative pressure gradient, acts on the fuel-gas solution. This is a factor that releases the gas from the solution saturated with it. This factor amplifies the sudden decompression process that typically occurs. At that point, the effect of gas desorption from the solution with nucleation of gas bubbles (desorption effect) occurs - in simplified terms, this is a reversal of the gas dissolution in fuel. An analogous mechanism takes place when a bottled of sparkling water is opened.

The rapidity of the effect is largely dependent on the rate of change of the aforementioned stimulus. This is a beneficial feature of the effect, since there is a significant pressure difference between the nozzle and the destination of fuel (combustion chamber). In addition, the fuel discharge from the injector occurs within a very short time and over a very short segment (length of the duct in the nozzle). The combination of both these factors leads to a very high rate of pressure change, and thus, a very large potential gradient, resulting in the amplification of the process. In such a dynamic process, the gas expands throughout the entire volume of the stream and is decompressed by way of pressure reduction. This results in an increase in the volume of microbubbles and the formation of the additional internal forces that tear the intermolecular bonds in the fluid apart, beneficially increasing the volume of the mixture stream. Therefore, a low rate of the process would be unfavorable - the forming microbubbles, distributed throughout the entire solution volume, would be merged.

As mentioned earlier, the dissolution of gas in Diesel takes place in the delivery section of the injection pump. This is also a significant part of the mechanism. The factors determining the occurrence and evolution of the dissolution process are temperature and the proper pressure. Under normal, atmospheric conditions, the influence of temperature is significant, since the solubility of gases in liquid is greater at lower temperatures [11]. The second of the factors mentioned is particularly important from the perspective of an engine - since gases are weakly soluble in liquids, it is necessary to subject both fluids to high pressure. Adopting the assumption that the process will be conducted at a constant temperature, accounting for the limited compressibility of fuel, it can be stated in general terms that the amount of gas which will be dissolved is proportional to the pressure of this gas. This results from Henry's law (1), which applies to the commonly used pressure values, accepting Bunsen's absorption coefficient for the set pressure. 


$$
V_{g}=\alpha_{V} \cdot V_{o l} \cdot p
$$

where: $V_{g}$ - volume of gas dissolved in oil

$\alpha_{v}-$ Bunsen's absorption coefficient

$V_{o l}$ - volume of oil,

$\rho$ - pressure.

The studies [7] conducted at the Poznan University of Technology confirmed the positive influence of the desorption effect on the operation of engines. Under the assumed injection pressure of $35 \mathrm{MPa}$ taken as an example, the rate of pressure growth was reduced by approx. $20 \%$ and the smoke density of exhaust gases was reduced by approx. 50\%. Moreover, the conducted tests demonstrated a reduction of the $\mathrm{CO}$ and $\mathrm{HC}$ emissions in association with the appropriate change of the charge's movement in the combustion chamber by approx. $100 \%$ and of $\mathrm{NO}_{\mathrm{x}}$ emissions by approx. $20 \%$.

However, these studies did not exhaust the subject. The injection pump responsible for initiating the process turned out to be a basic problem in the tests conducted. Achieving the desorption effect proved impossible in the standard pumps equipped with camshafts. The stroke and discharge of the pump were insufficient for an effective dissolution of the gas in the Diesel fuel during the suction stroke. It was therefore acknowledged that - in order for the mechanism of gas release from the fuel to occur - the high-pressure pump would have to have radically different proportions compared to the existing pumps. Hence, the research problem was to design a pump with a large stroke, enabling to obtain high discharge per pumping cycle, while simultaneously preserving the compact dimensions of the entire subassembly. This is the origin of the original pump design utilizing a hypocycloid power transmission.

The hypocycloid transmission (Fig. 1) consists of two wheels - the larger wheel (R) has interior toothing and the smaller wheel (r) has exterior toothing. Torque is applied to the smaller wheel, making it turn; however, the larger wheel cannot rotate around its axis. The smaller wheel moves over the circumference of the larger wheel, and any point on the smaller wheel's radius moves in a curve called the hypocycloid. In order to create the working drive of the pump, a special case of a hypocycloid transmission with a gear radius ratio of $\mathrm{R} / \mathrm{r}=2$ was applied. This selection of gears enables to achieve resultant linear motion.

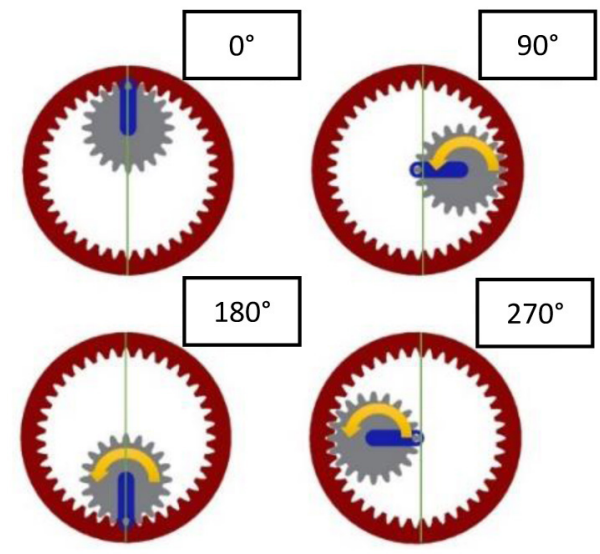

Fig. 1. Principle of operation of hypocycloid transmission

Using the above-mentioned power transmission concept, the pump design was created from the ground up. This solution was patented. In this scope, several variants were prepared, with 1 to 4 delivery sections. This article presents the simplest of them, based on 1 delivery section (Fig. 2).

The innovative pump has a main shaft (1) to which power is transmitted. A countershaft (2) is mounted in the main shaft in such a manner that mutual rotation of both components is possible. A toothed wheel with exterior toothing is found on the countershaft and meshes with toothed wheel (3), which is immobile and fixed to the pump's body. Support (4) is a component that interacts with the countershaft from the side of the delivery section. Moreover, mandrel (5) is mounted eccentrically in the countershaft, interacting with mount (6) via a bearing. The plunger (7) and its guiding element, situated so that it can slide within the cylinder of the delivery section, is fixed to this mount. Both the main shaft, support and mandrel have bearings (accordingly, (8), (9), (10) - Figure 3).

When designing the pump and entire injection system, which is to account for the application of the desorption effect, the unfavorable conditions under which systems of this type operate had to be kept in mind. Improper designing of subassemblies and inadequate fuel quality may lead to an accelerated wear, particularly in the vicinity of the precision friction pairs (delivery section of the pump, nozzle needle). Cavitation is another cause of the wear of components. This process propagates from microbubble nucleation sites, where the air contained in fuel evaporates. The main cause of the phenomenon is a change of velocity at the points where geometry changes 


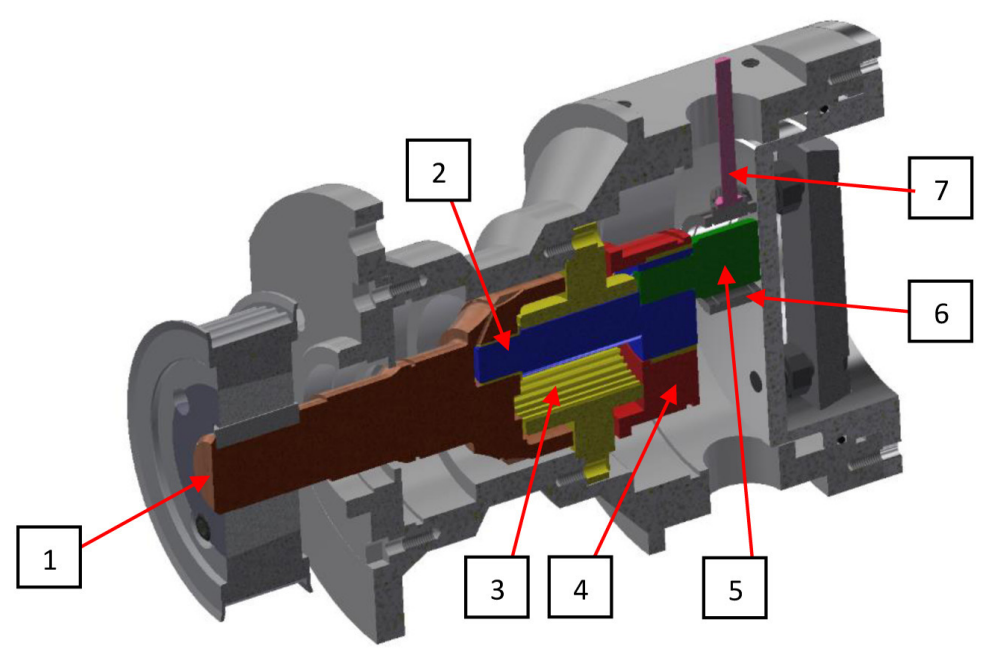

Fig. 2. Simplified model of hypocycloid pump presenting the most important components of the design: 1 - main shaft, 2 - countershaft, 3 - toothed wheel, 4 - support, 5 - mandrel, 6 - mount, 7 - plunger

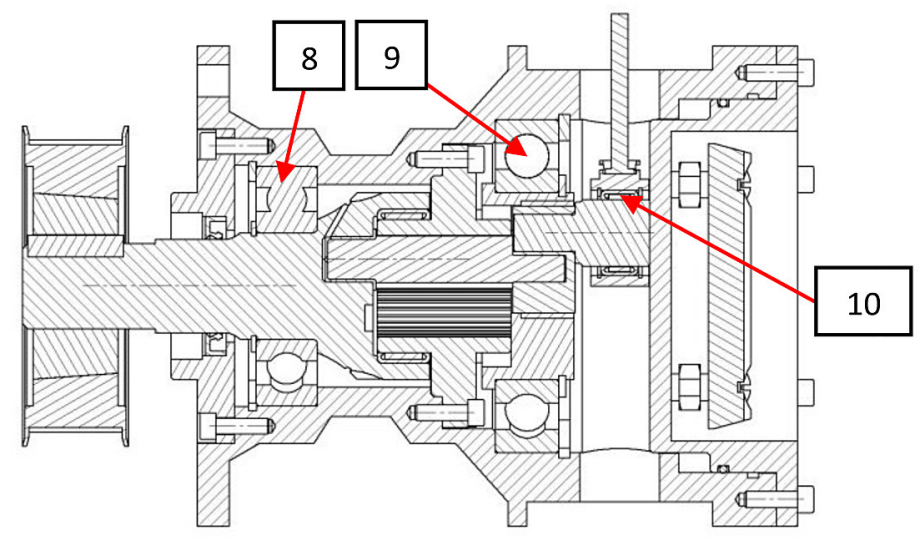

Fig. 3. Hypocycloidal drive pump - cross section with marked bearings

- as the pressure changes suddenly, a dynamic phase change from liquid to gas occurs. In the areas where cavitation occurs, the microbubbles of fuel vapors implode, leading to the cavitation wear manifesting as pitting on the metal surfaces.

In injection systems, this process pertains to both injectors and high-pressure pumps. In the standard injection pump solutions, the amount of air dissolved in the Diesel fuel is within the range of several percent - even such a small fraction of the entire fuel volume has an effect on the system's operation, causing the cavitation erosion. However, the unfavorable influence of cavitation is smaller in pumps than in injectors. On the other hand, it should be kept in mind that the consequences of cavitation may turn out to be much stronger if an equilibrium solution of liquid and gas is used, as is the case when the desorption effect is present. When designing a pump allowing for the use of Diesel oil with dissolved exhaust gases, all critical areas where the evaporation of fuel vapors may occur, had to be predicted. This aspect had to be considered in two tracks - on account of cavitation and its erosive effects as well as on account of the possibility of losing the potential shaping fuel injection with the application of the desorption effect.

It was therefore critical to properly design the delivery section (Fig. 4). The main components of the section are the cylinder and body. The piston's downward motion generates underpressure, which displaces the ball and spring in the one-way gas valve. At this point, the space above the piston is filled with gas that is sucked in. Further downward movement of the piston uncovers the channel feeding pressurized fuel, which is mixed with the gas contained in the cylinder, simultaneously causing its preliminary compression. The section is filled, which increases the pressure and closes the gas valve. 


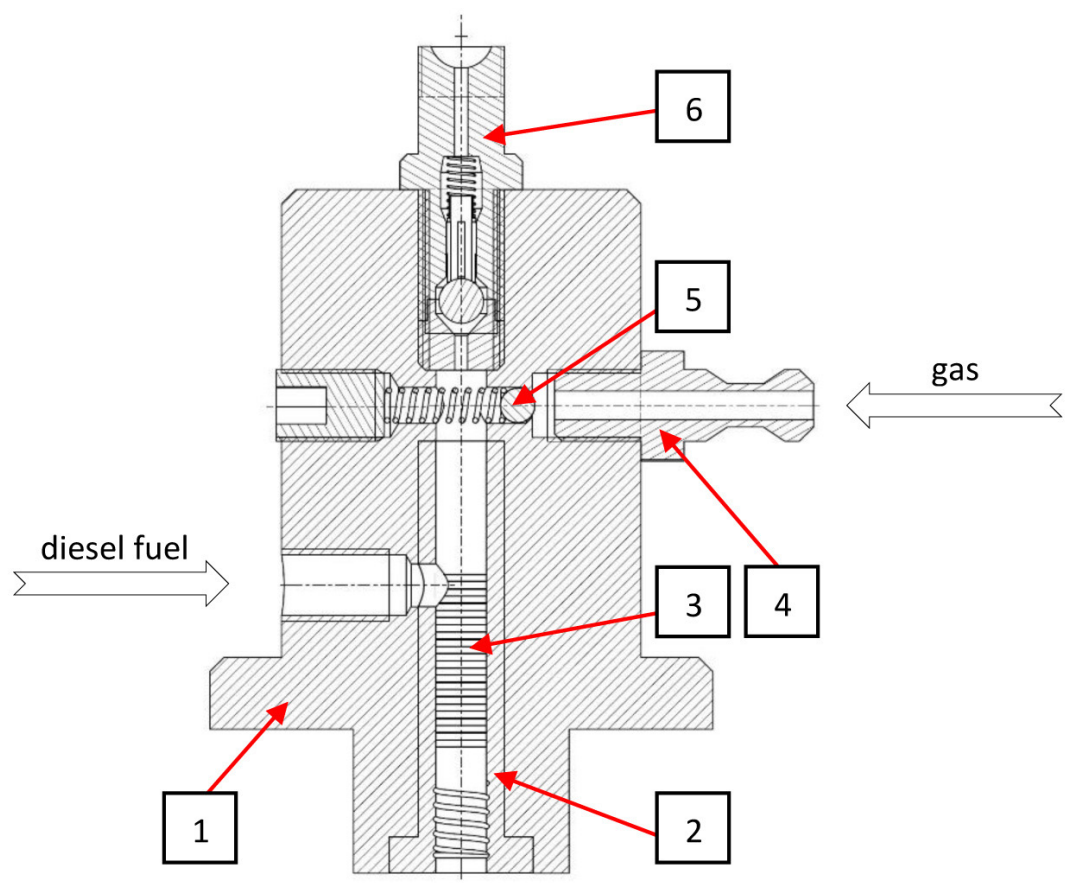

Fig. 4. Delivery section of hypocycloid pump: 1 - body of delivery section, 2 - cylinder, 3 - section labyrinth seal, 4 - gas stub pipe, 5 - one-way gas valve, 6 - one-way outlet valve (Fig. 5)

The upward motion of the piston closes the fuel feed channel and compresses the mixture further, and during this time, the gas dissolves in the fuel until an equilibrium solution is obtained. A complete dissolution of gas in Diesel oil is possible owing to the large stroke of the hypocycloid pump. After the initial pressing force on the spring in the one-way outlet valve is surmounted, the solution is pumped into the high-pressure line and then into the fuel rail.

The pump design therefore had to account for the potential cavitation nuclei in order to minimize this unfavorable phenomenon. In the pump pressure chamber itself, successive suction and discharge strokes result in the absence of the conditions for the local pressure reduction, which could potentially initiate cavitation. The one-way outlet valve is a problem worth considering in detail. This valve is among the sites in the high-pressure part of the pump where cavitation may occur by way of the equilibrium solution flowing out of the delivery section. According to the author, cavitation in the case of this valve may appear, in particular, during a sudden reduction of the discharge pressure, and the more dissolved gas is found in the liquid fuel, the greater the intensity of cavitation. Due to the fact that the hypocycloid pump is assumed to be adapted to the desorption effect, it must be investigated whether gas bubbles will form in the area of the outlet valve.

\section{Method of simulating two-phase flow in the one-way outlet valve of the hypocycloid pump}

The starting point for analysis of cavitation processes is the selection of the appropriate turbulence model, based on which the interactions between the scales of phenomena are defined: transport of momentum, mass, thermal energy. Hence, the k- $\varepsilon$ RANS turbulence model was adopted. The subject of modeling is a modification of the Navier-Stokes equations at every point to the form of a Reynolds equation by introducing to the equation averages over time and fluctuations as a sum to instant values of physical quantities [24]. Such a model is characterized by the speed of an algorithm and the stability of numerical processes [21]. The simulation method based on the two-equation Realizable k- $\varepsilon$ model was chosen to describe the phenomenon. This means that the model fulfills the assumptions of the Reynolds stresses, increasing the computational efficiency, is consistent with the laws of turbulent flows, hence the term "realizable". Therefore, the model is appropriate for the complex flows with rapid changes of fluid parameters, moderate turbulences, local disturbances, and thus, the flows similar to the environment of the valve operation, in which $\mathrm{k}$ determines the transport of turbulence energy and the $\varepsilon$ part determines the energy dissipation. 
However, it is also necessary to select a mathematical model of cavitation analyzed by the program solver. According to the Schnerr \& Sauer's methodology of computation, mass and momentum equations are solved for a single-fluid model that is treated as a mixture (defined in Fluent as "mixture") of the continuous phase, in this case, fuel, and the dispersive phase of gas, where only the conservation of mass equation is solved for the gas phase. Under the assumption that the flow velocities of the moving liquid and gas are equal, i.e. in the absence of slipping between phases, the share of the gas phase in the fluid is determined according to $[1,25]$ :

$$
\frac{\partial \alpha \rho_{v}}{\partial t}+\nabla\left(\alpha \rho_{v} u\right)=R_{e}-R_{c}
$$

where: $\alpha$-vapour volume fraction [-],

$\rho_{v}-$ vapour density $\left[\mathrm{kg} / \mathrm{m}^{3}\right]$

$u-$ mixture velocity $[\mathrm{m} / \mathrm{s}]$,

$t$ - time [s],

$R_{e}, R_{c}$ - source terms for evaporation and condensation, respectively $\left[\mathrm{kg} / \mathrm{m}^{3} \mathrm{~s}\right]$.

The authors introduced the dependencies describing the source terms of mass conservation $R_{e}, R_{c}$ to the above-mentioned equation by using coefficient $\alpha$. It describes the volumetric share of vapors - gaseous phases in the fuel - liquid, by defining the number of bubbles per unit of fluid and bubble radius according to the equations $[10,26]$ :

$$
\begin{gathered}
\alpha=\frac{n_{B} \frac{4}{3} \Pi r_{B}^{3}}{1+n_{B} \frac{4}{3} \Pi r_{B}{ }^{3}} \\
r_{B}=\left(\frac{\alpha}{1-\alpha} \frac{3}{4 \Pi} \frac{1}{n_{B}}\right)^{\frac{1}{3}}
\end{gathered}
$$

where: $n_{B}$ - number of bubbles per volume of liquid [-]

$r_{B}-$ bubble radius $[\mathrm{m}]$,

In the analyzed case, the fuel that flows through the valve after the discharge stage in the high-pressure pump is treated as a single-fluid liquid with a very small amount of undissolved air bubbles. It was therefore assumed that the number of bubbles after the dissolution stage is very small as a result of their disappearance into the volume of fuel and due to the fact that the residual bubbles remaining trapped in the solution have a very small radius on the order of $10^{-6} \mathrm{~m}$.

The share of vapors in the fluid is ultimately determined on the basis of equation (2), enriched only by the $n_{b}$ and $r_{b}$ defined for the source terms $[10,26]$ :

$$
\begin{aligned}
& R_{e}=\frac{\rho_{l} \rho_{v}}{\rho} \alpha(1-\alpha) \frac{3}{r_{B}} \sqrt{\frac{2}{3} \frac{p_{S}-p}{\rho_{l}}} \\
& R_{c}=\frac{\rho_{l} \rho_{v}}{\rho} \alpha(1-\alpha) \frac{3}{r_{B}} \sqrt{\frac{2}{3} \frac{p-p_{S}}{\rho_{l}}}
\end{aligned}
$$

where: $\rho_{l}-$ density of liquid phase $\left[\mathrm{kg} / \mathrm{m}^{3}\right]$,

$\rho$-density $[\mathrm{kg} / \mathrm{m} 3]$,

$p_{s}-$ pressure of saturation $[\mathrm{Pa}]$

$p$ - pressure in the flow $[\mathrm{Pa}]$.

The simulation of two-phase flow concerns the one-way outlet valve found on the outlet from the pump - the equilibrium solution of Diesel oil and gas flows through this valve. The valve design contains a moving ball - this solution is analogous to the one applied in many generations of common rail injection pumps. The occurrence of cavitation and its intensity largely depends on the valve design. The valve design proposed for the hypocycloid pump (Fig. 5) was subjected to the CFD analysis by means of Ansys Fluent R18.2 software. The main goal of simulation was to verify the potential areas of air bubble formation in the discussed fuel.

The volume of fluid was discretized by division into 504260 elements and 126689 nodes along with near-wall layers (Fig. 6). Depending on the variant of the conducted simulation, different cavitation pressure values (arising from the volume of dissolved air in the fuel) and inlet and outlet pressure values were adopted. A stationary flow model, i.e. without turbulence on the valve inlet and for a fully open valve (ball fully displaced from closed position), was also adopted.

\section{RESULTS AND DISCUSSION}

Utilizing the operation of the hypocycloid pump in an injection system working analogously to common rail systems is planned. In relation to this, the application of a pressure accumulator is assumed, as is the case in the conventional 


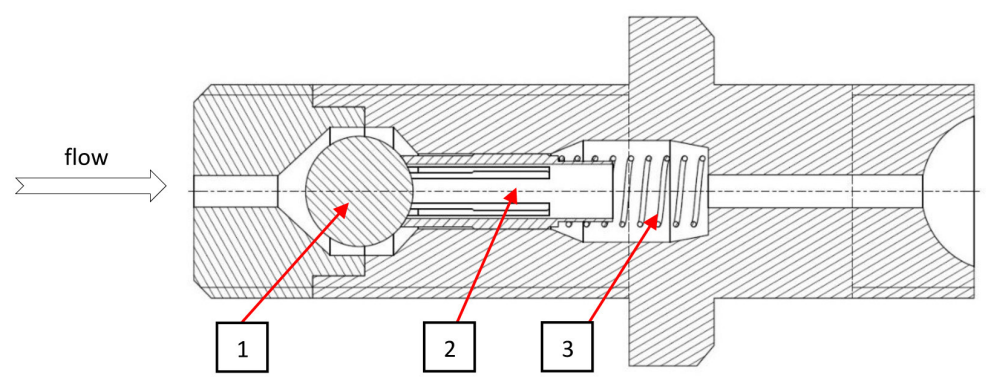

Fig. 5. Model of the conceptual design of the hypocycloid pump one-way outlet valve: 1 - ball, 2 - cage, 3 - extension-adjusting spring

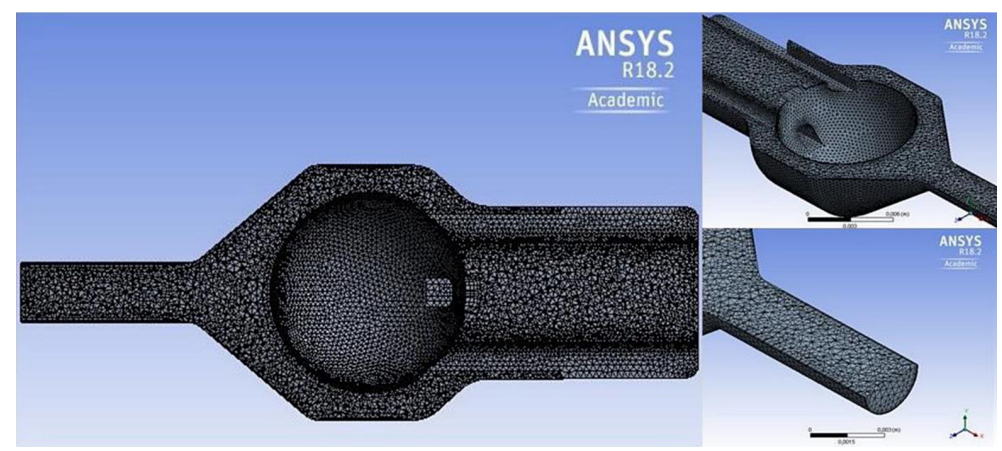

Fig. 6. Discretization of outlet valve fluid volume

solution. On the one hand, the release of gas from the fuel may be difficult in the high-pressure part of the system, starting from the hypocycloid pump up to the nozzle (including the accumulator). On the other hand, even in the case of conventional systems, there is a certain share of air in the fuel, which may lead to the formation of the cavitation nuclei. In addition, considering the possibility of application of the desorption effect, and hence, the presence of a substantial share of gas (e.g. air) in the fuel, this problem may be exacerbated, leading to the occurrence and amplification of the cavitation process. In this case, air is intentionally introduced into the system and not the result of leaks or fuel vapor saturation as has been the case until now. In relation to this, the problem requires evaluating whether the air content dissolved in the fuel, i.e. Diesel oil, has an influence on the occurrence of the cavitation phenomenon.

In this scope, a simulation was conducted, in which two variants were distinguished. The first of them pertained to the conditions of a full cycle of the delivery system. One of the assumptions associated with the application of the desorption effect is the possibility of reducing the injection pressures (less than $100 \mathrm{MPa}$ ) with respect to the conventional systems. This is intended to relieve the burden on the systems in order to increase their operating lifetime. Despite this, it was assumed that the fuel will be discharged by the hypocycloid pump at a pressure of $150 \mathrm{MPa}$ in order to evaluate the influence of the effect on the possibility that cavitation nuclei will form with a certain surplus. This is the pressure under which the fuel will flow through the simulated, fully open one-way valve (inlet). The value of instant pressure in high-pressure lines and in the injection rail (outlet) was adopted at the same level. The pressure pulsations and mass loss phases arising from injection were omitted - hence, stationary flow through the valve was assumed.

Three equilibrium pressure points, i.e. 1, 5, $10 \mathrm{MPa}$ were selected from the solubility curve (Fig. 7) of air in Diesel oil [8,9] - these were, accordingly, points A, B, C, or the points at which air is completely dissolved in Diesel oil. These points were used in the simulation of cavitation in the one-way valve. Within this range, a characteristic illustrating the value of the fraction of released air bubbles (Fig. 8) and a characteristic illustrating the fluid flow velocity through the valve (Fig. 9) were obtained.

The simulations confirmed the absence of the cavitation nuclei. This arises from the fact that static pressure is maintained in the valve at a much higher level than the saturation pressure. The simulation presented in the figure (Fig. 8) confirms that the entire volume is occupied by the 


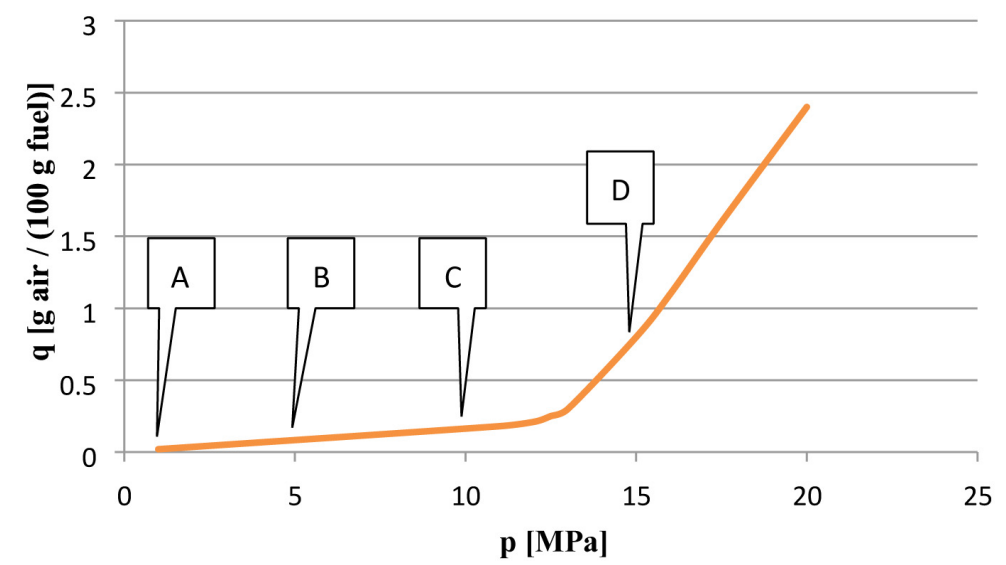

Fig. 7. Solubility coefficient of air in Diesel oil

air-Diesel oil solution, i.e. solution in equilibrium state - this is indicated by the absence, in every considered variant, of the fraction of released gas bubbles. Thus, the cavitation characteristic partially confirms the assumption that there is no risk of the air bubbles forming and imploding at a later stage in the case of full flow through the valve, regardless of the volume of air that will be dissolved in the hypocycloid pump.

The second stage of the simulation assumed a special case, i.e. the start-up phase of the engine, and thus, the instant in which the fuel with nominal pressure is reaching the accumulator or lines. The share in time of this stage of engine operation is substantially smaller than the share of the situation presented in the first stage of simulation. This is, however, a stage in which the conditions fostering cavitation are present. In this case, fuel pressure on the inlet, and thus in the one-way valve (inlet), at a level of $150 \mathrm{MPa}$ was assumed, and from the side of lines (outlet), this value amounted to $20 \mathrm{MPa}$. The fourth point, i.e. $D$ with a value of $15 \mathrm{MPa}$, was selected on the curve of the solubility curve (Fig. 7). The results are presented analogously as for the first stage of simulation (Fig. 10 and 11).
The obtained cavitation characteristics show that, at a higher equilibrium pressure of the solution, or at the pressure at which total dissolution of air in Diesel oil occurs, for the situation of engine start-up, the cavitation nucleation areas are larger during the fuel flow through the valve. The first reason for this is an increased equilibrium pressure during dissolution, which is required for the dissolution of a greater mass of air. The second cause arises from the areas in the valve - a static pressure drop below the equilibrium pressure value was noticeable. This proves the hypothesis that the main problem in the issue of cavitation in the hypocycloid pump one-way outlet valve may be the improper design of this valve. On the other hand, the small critical areas appearing as fuel flows around the ball do not have a significant influence on the gas fraction, and thus, on cavitation. The gas phase mainly forms near the inlet and in the case of a small volume change. It can therefore be supposed that the proper shaping of the inlet geometry will enabled to eliminate the occurrence of this phenomenon.

The effect of gas desorption from the solution with nucleation of gas bubbles is a mechanism with high potential with regard to the issue of

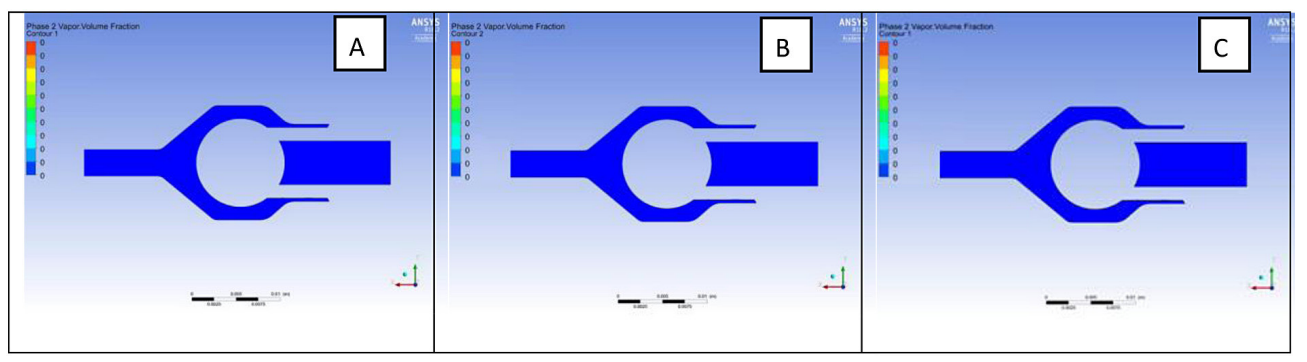

Fig. 8. Cavitation characteristic of the outlet valve. The points of stationary flow simulation illustrating the value of released air bubble fractions: A, B, C, corresponding to the equilibrium pressure $[8,9]$ of the air-Diesel oil solution for a complete cycle of the delivery system 


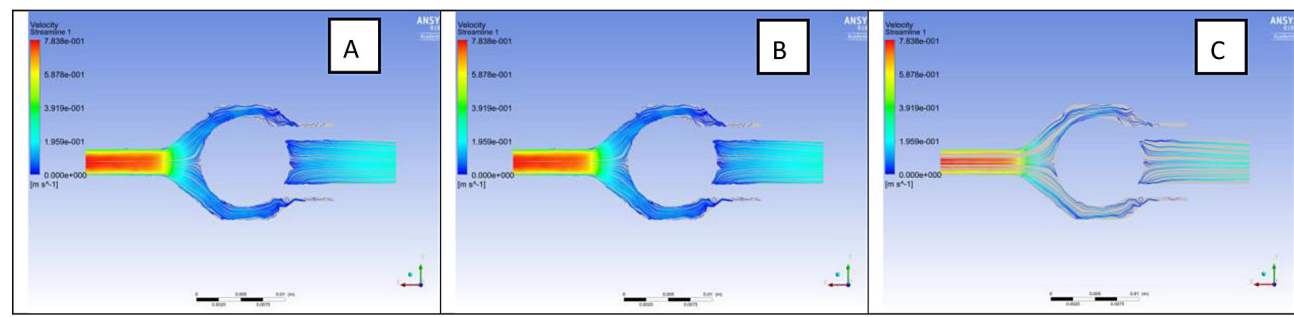

Fig. 9. Cavitation characteristic of the outlet valve. The points of stationary flow simulation illustrating flow rate: $\mathrm{A}, \mathrm{B}, \mathrm{C}$, corresponding to the equilibrium pressure $[8,9]$ of the air-Diesel oil solution for a complete cycle of the delivery system

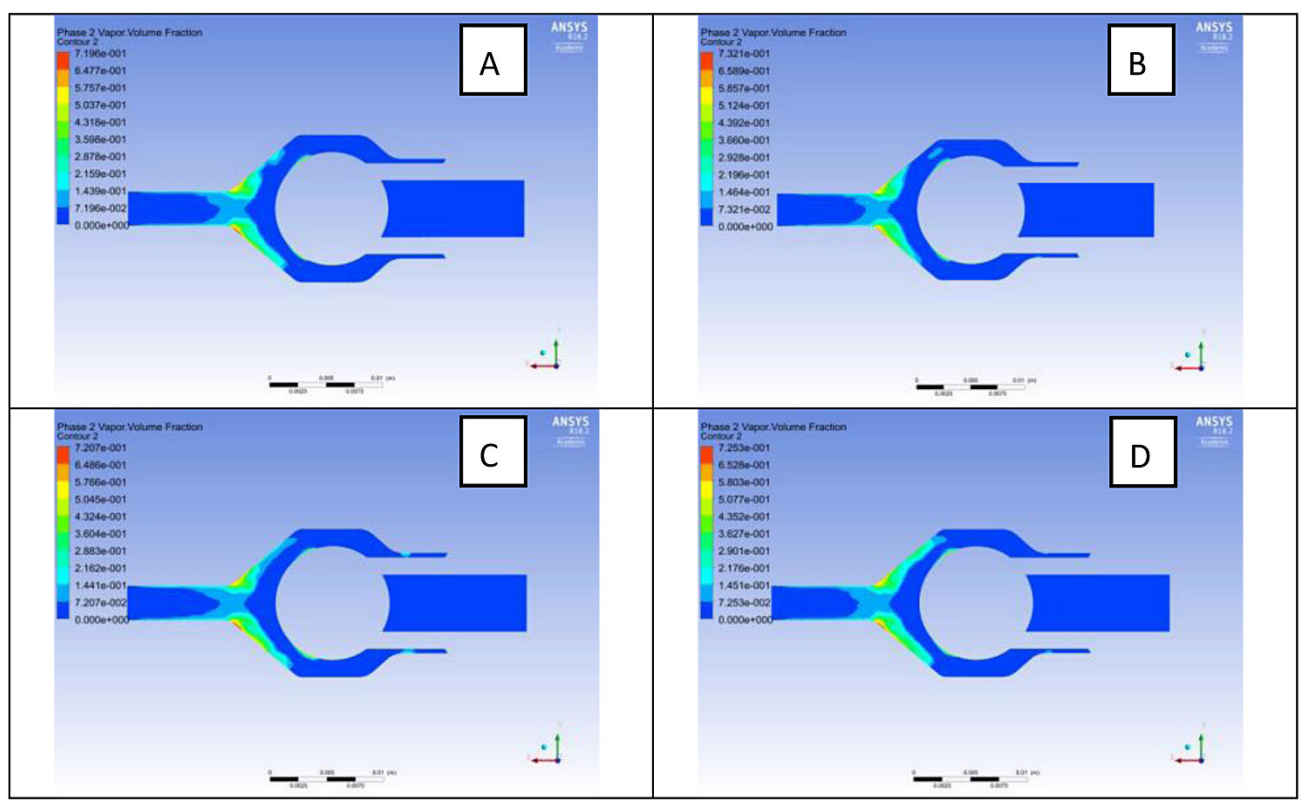

Fig. 10. Cavitation characteristic of the outlet valve. The points of stationary flow simulation illustrating the value of released air bubble fractions: A, B, C, corresponding to the equilibrium pressure $[8,9]$ of the air-Diesel oil solution for the initial operation of the delivery system - engine start-up

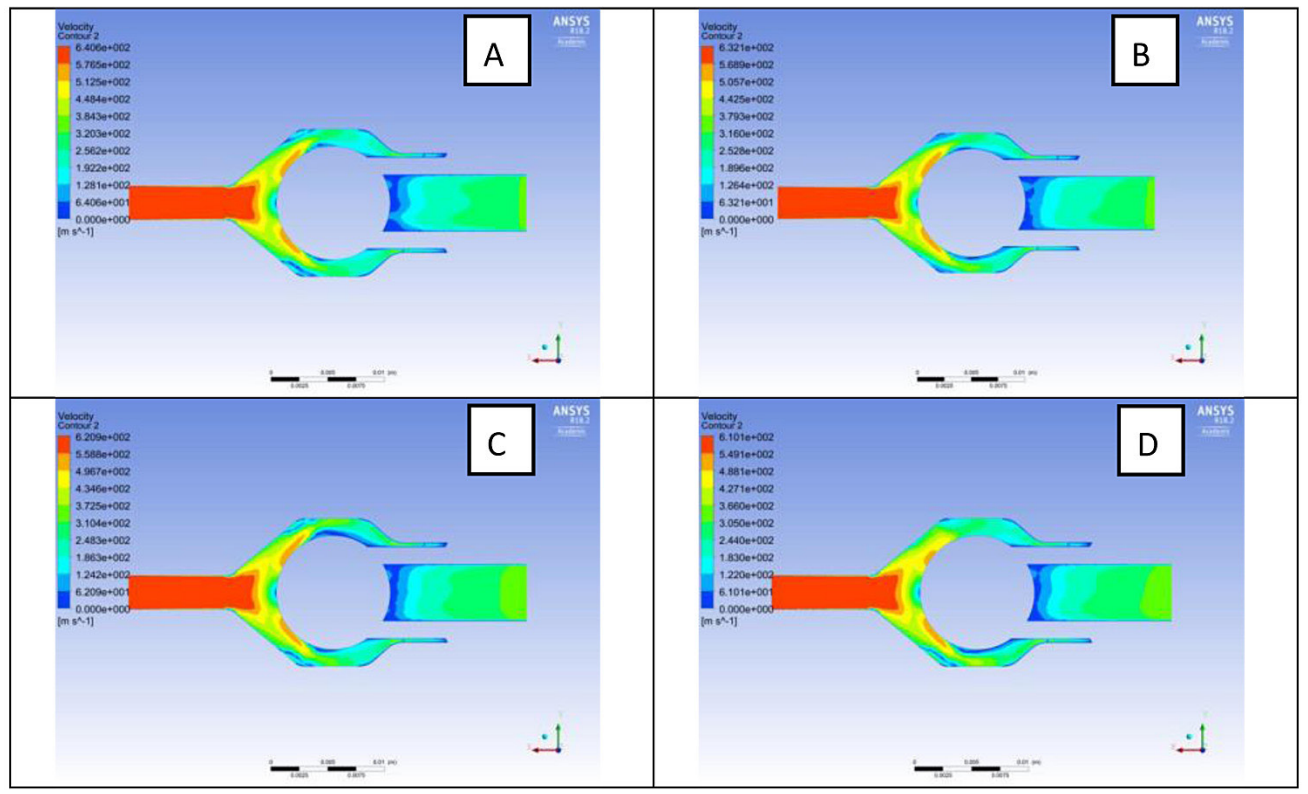

Fig.11. Cavitation characteristic of the outlet valve. The points of stationary flow simulation illustrating flow rate: A, B, C, corresponding to the equilibrium pressure $[8,9]$ of the airDiesel oil solution for the initial operation of the delivery system - engine start-up 
improving the functional and emission parameters of the compression-ignition engines. This is a relatively new phenomenon that has been studied to a limited extent. Utilization of the effect that accompanies the release of gas dissolved in the fuel is the most important mechanism planned for application in the newly designed, original pump with hypocycloid power transmission

\section{CONCLUSIONS}

The effect of gas desorption from the solution with nucleation of gas bubbles is a mechanism with a high potential with regard to the issue of improving the functional and emission parameters of the compression-ignition engines. This is a relatively new phenomenon that has been studied to a limited extent when it comes to the engine issues. Utilization of the effect that accompanies the release of gas dissolved in the fuel is the most important mechanism planned for application in the newly designed, original pump with hypocycloid power transmission. The problem undertaken in this article concerned the possibility of the formation of the cavitation nuclei in the pump component potentially under the greatest burden, i.e. check valve. The simulations performed for the standard injection pressures under full load confirmed the absence of the cavitation nuclei. They appeared in the second analyzed phase, i.e. the engine start-up. In the author's opinion, based on a comparison with the cavitation mechanism occurring in nozzles, it can be stated that, in this case, this phenomenon can be considered safe, particularly considering the potential for optimization of the one-way outlet valve design. Such a state can also be acknowledged as safe from the perspective of the desorption effect - no thermodynamic potential will be lost by the air-Diesel oil solution inside the pump over the course of a full engine work cycle as a result of choking in the valve. Further research should involve the analysis of the phenomenon of the wave cavitation and precise determination of the physical properties characterizing the equilibrium fluid.

\section{REFERENCES}

1. ANSYS FLUENT 2015 User's guide

2. Bajerlein M., Rymaniak L., Swiatek P., Ziolkowski A., Daszkiewicz P. and Dobrzynski M. Modifica- tion of a Hybrid City Bus Powertrain in the Aspect of Lower Fuel Consumption and Exhaust Emissions. Experimental and Applied Mechanics (EAM) Book Series: Applied Mechanics and Materials, Volume: 518, 108-113.

3. Beatrice C., Di Iorio S., Guido C., Mancaruso E. et al. Alternative Diesel Fuels Effects on Combustion and Emissions of an Euro4 Automotive Diesel Engine. SAE Int. J. Engines, 2(2), 2010, 542-561.

4. Buchal C., Karl H-D., and Sinn H-W Kohlemotoren, Windmotoren und Dieselmotoren: Was zeigt die CO2-Bilanz? ifo Schnelldienst, 8/2019, 2019, $40-55$.

5. Kamasamudram K., Henry C., Currier N., and Yezerets, A. N2O Formation and Mitigation in Diesel Aftertreatment Systems. SAE Int. J. Engines, 5(2), 2012, 688-698.

6. Kamimoto T., Murayama Y., Minagawa T. and Minami T. Light scattering technique for estimating soot massloading in diesel particulate filters. International Journal of Engine Research, Vol. 10, 2009, 324-336.

7. Kozak W., Bajerlein M. and Markowski J. Weryfikacja koncepcji wspomagania mechanizmu rozpylenia oleju napędowego rozpuszczonym w nim powietrzem. Combustion Engines, 1/2006 (124), 2006, 21-37.

8. Kozak W. Kształtowanie parametrów wtrysku do silników o zapłonie samoczynnym. Poznan Univeristy of Technology Publishing House, 2008.

9. Kozak W., Markowski J. Współczynnik rozpuszczalności powietrza i spalin w oleju napędowym. Archiwum Spalania, 3(2-4), 2003, 50-61.

10. Kozubkova M., Bojko M., Jablonska J., Homa D. and Tuma J. Experimental research of multiphase flow with cavitation in the nozzle. EPJ Web of Conferences 114, 02058, 2016, 1-8.

11. Kudźma Z. and Mackiewicz O. Badanie zjawiska kawitacji w pompach wyporowych. Pomiary Automatyka Robotyka, R. 20, Nr 1/2016, 2016, 17-23

12. Kuszewski H., Jaworski A., Ustrzycki A., Lejda K., Balawender K. and Woś P. Use of the constant volume combustion chamber to examine the properties of autoignition and derived cetane number of mixtures of diesel fuel and ethanol. Fuel, Volume 200, 2017, 564-575.

13. Matsumoto S., Yamada K. and Date K. Concepts and Evolution of Injector for Common Rail System. SAE Technical Paper 2012-01-1753, 2012, 1-14.

14. Meek G., Williams R., Thornton D., Knapp P. and Cosser S. F2E - Ultra High Pressure Distributed Pump Common Rail System. SAE Technical Paper, 2014-01-1440, 2014, 1-8.

15. Merkisz J., Bajerlein M., Kozak W. and Markowski J. The Influence of CNG Dissolved in the Diesel 
Fuel on the Combustion Process and Concentration of Toxic Compounds in Exhaust Gas. SAE Technical Paper, 2008-01-1815, 2008, 1-8.

16. Merkisz J., Bajerlein M. and Kozak W. Dissolving Oxygen in Diesel Fuel as a Way to Make Road Transport More Environmentally Friendly. WIT Transactions on The Built Environment, Vol 101, 2008, 325-334.

17. Merkisz J., Kozak M., Kozak W. and Bajerlein M. Dissolving Gas in Diesel Fuel as a Way for Fuel Oxygenation and Diesel Exhaust Emissions Reduction. SAE Technical Paper, 2007-01-2049, 2007, 1907-1914.

18. Merkisz J., Kozak W., Bajerlein M. and Markowski J. The Influence of Exhaust Gases Dissolved in Diesel Oil on Fuel Spray Particulary Parameters. SAE Technical Paper, 2007-01-0488, 2007, 1-9

19. Merkisz J., Mizera J., Bajerlein M., Rymaniak L. and Maj P. The Influence of Laser Treatment and the Application of Reduced Pressure Force Piston Rings on the Engine Exhaust Emissions under the Conditions of Engine Lubrication with Different Engine Oils. Applied Mechanics and Materials, Trans Tech Publications, Vol. 518, 2014, 102-109.

20. Messagie M. Life Cycle Analysis of the Climate Impact of Electric Vehicles. Transport \& Environment - Raport, 2014, 1-15.

21. Mocek P. Analiza numeryczna zaworu kulowego - charakterystyka przepływowa i kawitacyjna. Pomiary Automatyka Kontrola, vol. 57, nr 1/2011, 2011, 97-100.
22. Nagata K. State-Of-Art Technologies For Diesel Common Rail System. SAE Technical Paper 2004-28-0068, 2004, 442-447.

23. Ottinger N., Schmidt N., and Liu Z. Understanding System- and Component-Level N2O Emissions from a Vanadium-Based Nonroad Diesel Aftertreatment System. SAE Int. J. Engines, 10(4), 2017,1808-1814.

24. Paszko M. and Łygas K. Współczesne metody modelowania przepływów turbulentnych w otoczeniu poruszającego się autobusu miejskiego. Autobusy: technika, eksploatacja, systemy transportowe, 12/2016, 2016, 1269-1272.

25. Puffary B. Numerical modelling of cavitation, design and analysis of high speed pumps. Educational Notes RTO-EN-AVT-143, paper 3, 2006, 1-55.

26. Schnerr G. H., Sauer J. Physical and Numerical Modelling of Unsteady Cavitation Dynamics. ICMF-2001, 4th International Conference on Multiphase Flow, New Orleans, USA 2001, 1-12.

27. Wloka J., Pflaum S., and Wachtmeister, G. Potential and Challenges of a 3000 Bar Common-Rail Injection System Considering Engine Behavior and Emission Level. SAE Int. J. Engines, 3(1), 2010, 801-813.

28. Woś P., Balawender K., Jakubowski M., Kuszewski H., Lejda K. and Ustrzycki A. Design of Affordable Multi-Cylinder Variable Compression Ratio (VCR) Engine for Advanced Combustion Research Purposes. SAE Technical Paper, 2012-01-0414, $2012,1-10$. 